\title{
Surto de peste bubônica na localidade de Jacocha, Huancabamba, Penú
}

\author{
Outbreak of bubonic plague in -Jacocha, Huancabamba, Perú \\ Victor Alva Dávalos ${ }^{1}$, Marco Arrieta Torres', Carlos Olguín Mauricci', \\ Victor Alberto Laguna-Torres ${ }^{2}$ e Mónica Pun Chinarro²
}

\begin{abstract}
Resumo As alterações climáticas produzidas no norte do Perú devidas ao Fenômeno El Niño (ENSO), ocasionaram variacões no volume das safras, redistribuição do curso dos rios e provavelmente aumento da população de roedores. Em fevereiro de 1999, em uma comunidade indígena em Jacocha, Huancabamba, na serra de Piura, Perú, surgiu um surto de peste com cinco casos humanos, um dos quais faleceu. O diagnóstico foi confirmado pela sorologia (hemaglutinação passiva). A presença de anticorpos em cães de localidades próximas de Jacocha confirmaram a circulação da Yersinia pestis na área. O surto foi debelado pela rápida atuação das autoridades sanitárias locais. O episódio após silêncio epidemiológico por mais de quatro anos, mostrou a necessidade de reforçar o sistema de vigilância epidemiológica de peste nesta área.

Palavras-chaves: Yersinia pestis. Peste bubônica.
\end{abstract}

Abstract Climatic alterations arising in the north of Perú as a result of the El Niño phenomenon (ENSO) have caused variations in the crop volume, changes in the direction of rivers and probably an increase in the rodent population. In February 1999, in a native community in Jacocha, Huancabamba, Piura's mountains, Perú, an outbreak of bubonic plague appeared with five human cases, one of which lead to death. The diagnosis was confirmed by serology (passive hemaglutination). The presence of antibodies in dogs of localities close to Jacocha has confirmed the circulation of Yersinia pestis in the region. The outbreak was controlled by the local sanitary authorities' prompt action. This episode, after an epidemiological silence for more than four years, showed the necessity of intensifying the plague epidemiological surveillance system in this area.

Key-words: Yersinia pestis. Bubonic plague.

\section{ANTECEDENTES EPIDEMIOLÓGICOS}

No verão de 1998, a presença do Fenômeno de EI Niño (ENSO) incrementou as chuvas em todo o norte do Perú, ocasionando profundos danos na infraestrutura viária, na produção agrícola e nas moradias dos habitantes da área. Também, afetou as populações animais no meio ambiente. No caso dos roedores, a destruição dos abrigos levou-os a procura de proteção nas habitações humanas com o conseguinte aumento do contato entre $o$ animal e 0 homem. Tais alterações ecológicas incrementaram o risco de aparição de doenças produzidas pelos roedores.

No Perú, nas áreas de serra as chuvas constantes se apresentam nos meses de dezembro a março.

O Perú encontra-se dividido politicamente em departamentos. Piura é um departamento situado ao norte do país e é lá onde se apresentou um surto de peste
(Figura 1). O ENSO atingiu Piura ocasionando numerosos danos.

Piura como departamento têm sete províncias e uma população, estimada, em 1999, de 1.365 .765 habitantes. A província de Huancabamba, onde se encontra Jacocha, localidade onde ocorreu o surto, tem 120.000 habitantes e o distrito de Huancabamba conta com 25.797 habitantes.

No Departamento de Piura tem sido observados casos de peste desde a introdução da doença no Perú na primeira década do século XX, quando foram afetadas as áreas portuárias e cidades da costa. Posteriormente, a doença se fez silvestre com ciclos enzoóticos. No início da década de 80, apresentou-se uma epidemia importante que comprometeu a província de Huancabamba, área

\footnotetext{
1. Dirección de Epidemiologia, Laboratório Regional e Programa de Control de Zoonosis DISA PIURA I; 2. Oficina General de Epidemiologia, Lima, Peru. Endereço para correspondência: Dr. Victor Alva Dávalos. Av Cesar Vallejo 159 Urb San Jose - Piura, Peru.

Fax: (01) 4330081

e-mail: valva@oge.sld.pe; alaguna@oge.sld.pe

Recebido para publicação em 16/6/2000.
} 


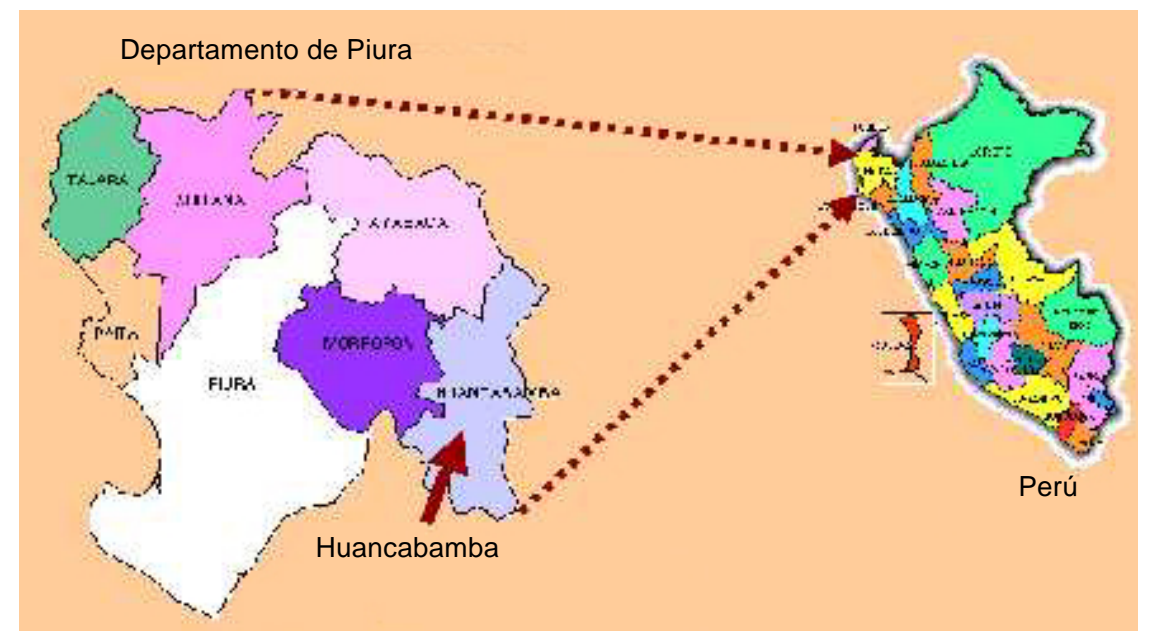

Figura 1 - Localização da Provincia de Huancabamba-Piura, Perú

que já tinha antecedentes de peste ${ }^{6}$. Os últimos casos prováveis de peste na jurisdição de Piura foram notificados no ano de 1995 no Distrito de Salitral, Província de Morropón.

Características da área do surto. A localidade de Jacocha tem uma altitude de $2.900 \mathrm{~m}$ e chuvas de moderada intensidade, temperatura de $6-10^{\circ} \mathrm{C}$. O acesso à localidade se faz por caminhos não asfaltados nos períodos secos, porém intransitáveis na época de chuva. No momento do surto, Jacocha somente era acessível por animais de carga ou a pé numa viagem de 4 a 7 horas. A atividade econômica da população é a agricultura (batata, milho, feijão, oca, olluco, etc) e a pecuária (bovinos, ovinos, eqüinos). Entre os roedores são encontrados Rattus rattus, Akodon sp. e Oryzomys sp.

Descrição do surto. Na Semana Epidemiológica (SE) 9 de 1999 (fevereiro), a Dirección de Salud (DISA) Piura I, notificou à Oficina General de Epidemiologia cinco casos prováveis de peste procedentes da localidade de Jacocha, Província de Huancabamba, Piura.

As pesquisas epidemiológicas mostraram que aparentemente, depois de manusear um roedor que se encontrava nas imediações de seu domicílio, o homem considerado como caso índice faleceu em 10/2/99 com quadro febril acompanhado por tosse e alterações bronquiais. Entre os presentes no velório, três adultos apresentaram doença febril e tumorações dolorosas na região inguinal. Duas crianças de 13 e 5 anos, respectivamente, filhos de uma das mulheres presentes nesse velório foram também, inicialmente, catalogadas como casos prováveis de peste (Tabela 1). Posteriormente, como a sorologia fosse negativa o caso no 4 foi excluído.

Os profissionais de saúde tomaram conhecimento da morte do habitante somente após dois dias, pela

Tabela 1 - Principais características dos cinco pacientes identificados como casos prováveis e confirmados de peste em Jacocha. Piura, Peru. 1999.

\begin{tabular}{|c|c|c|c|c|c|c|}
\hline \multirow[t]{2}{*}{ № } & \multirow[t]{2}{*}{ Ocupação } & \multirow{2}{*}{$\begin{array}{c}\text { Idade em } \\
\text { anos e sexo }\end{array}$} & \multirow{2}{*}{$\begin{array}{l}\text { Localização } \\
\text { do bubão }\end{array}$} & \multicolumn{2}{|c|}{$\begin{array}{c}\text { Sorologia } \\
\text { hemaglutinação } \\
\text { passiva }\end{array}$} & \multirow{2}{*}{$\begin{array}{l}\text { Antecedente } \\
\text { epidemiológico }\end{array}$} \\
\hline & & & & $\begin{array}{c}1^{\text {a }} \text { amostra } \\
16 / 3 / 99 \\
\end{array}$ & $\begin{array}{c}2^{a} \text { mostra } \\
23 / 4 / 99 \\
\end{array}$ & \\
\hline 1 & agricultor & $\begin{array}{c}48 \\
\text { masculino }\end{array}$ & $\begin{array}{l}\text { inguinal } \\
\text { direito }\end{array}$ & $1 / 512$ & $1 / 256$ & $\begin{array}{c}\text { esteve presente no velório. } \\
\text { lavou as roupas do óbito. } \\
\text { seu pai e dois irmãos morreram } \\
\text { de peste há } 18 \text { anos em Jacocha }\end{array}$ \\
\hline 2 & do lar & $\begin{array}{c}40 \\
\text { feminino }\end{array}$ & inguinal esquerdo & $1 / 256$ & $1 / 128$ & esteve presente no velório \\
\hline 3 & estudante & $\begin{array}{c}13 \\
\text { masculino }\end{array}$ & axilar direito & $1 / 256$ & não foi feita & filho do caso $n^{\circ} 2$ \\
\hline 4 & do lar & $\begin{array}{c}5 \\
\text { feminino }\end{array}$ & axilar direito & negativa & negativa & filho do caso $n^{\circ} 2$ \\
\hline 5 & agricultor & $\begin{array}{c}27 \\
\text { masculino }\end{array}$ & inguinal & $1 / 256$ & não foi feita & esteve presente no velório \\
\hline
\end{tabular}

O caso índice (óbito) não foi avaliado. 
comunicação do vigilante comunitário de saúde de Jacocha que informou à enfermeira do Posto de Saúde (PS) de Cascamache.

A mãe do caso $n^{\circ}$ 1, que há dezoito anos havia perdido dois familiares por peste, reconheceu a doença. Esta experiência prévia permitiu que os profissionais de saúde ficassem sabendo do caso.

Não foi possível obter maiores dados clínicos do caso índice pela negativa da família em fornecê-los. Oito dias após, surgiu outro caso em um paciente de 48 anos de idade na mesma localidade e outros, respectivamente, no $10^{\circ}, 11^{\circ}, 12^{\circ}, 13^{\circ}$ dia após a morte do caso índice. A investigação retrospectiva (48-72 horas após) mostrou que os pacientes apresentaram quadro febril agudo e tumorações dolorosas nas regiões inguinal ou axilar. Embora todos já tivessem recebido estreptomicina e cloranfenicol foi coletado sangue para hemocultura, com resultados negativos. Em nenhum deles foi feito aspirado do suco bubonático para cultura.

Aproximadamente, 48 horas após o falecimento do caso índice, uma equipe multidisciplinar de intervenção rápida do Hospital de Huancabamba mobilizou-se, a pé, para Jacocha fazendo análise da situação local e identificando todos os casos prováveis de peste na localidade.

O número de contatos identificados e tratados entre os presentes ao velório e familiares foi de 90 . Entre os contatos houve 15 profissionais das equipes de saúde. A taxa de ataque foi de 5,6\%, a taxa de letalidade de $16,7 \%$ sendo a taxa de incidência em Jacocha de 0,2 casos por
1.000 habitantes e a taxa de incidência distrital de 0,2 casos por 1.000 habitantes. Os cinco casos prováveis, que apresentaram febre e bubões, foram avaliados na fase de remissão da doença.

Realizou-se uma pesquisa qualitativa (grupos focais de homens e mulheres por separado) com os habitantes da localidade de Jacocha para poder determinar a percepção de risco, crenças e atitudes frente à peste, como padrões comunitários determinantes do conhecimento e forma de disseminação da doença que será motivo de outra publicação.

Foram colhidas amostras de sangue e de tecidos para pesquisa de Yersinia pestis em roedores. Dos cães pertencentes às casas próximas e às localidades vizinhas, foram obtidas amostras de sangue com tiras Nobuto, que são pequenas fitas feitas especialmente para obter mínimas quantidades de sangue do animal, e que são facilmente transportadas em envelopes, para processamento no Laboratório Regional de Saúde de Piura (LARESA)

Nos roedores não foi possível isolar a $Y$. pestis. Foram encontrados anticorpos contra a Y.pestis em 11 cães das localidades de Jicate Bajo (3), Matara (1), Calderón (1), Pundín (3), Laguna (1) e Saquirayuc (2).

A equipe multidisciplinar composta por profissionais do Programa de Controle de Zoonoses e pessoal do Hospital de Huancabamba, iniciou a despulização das moradias e o controle de roedores e pulgas, remetendo as pulgas colhidas ao laboratório de referência regional. A alta epidemiológica foi dada no dia oito de março de 1999.

\section{DISCUSSÃO}

Pelas características clínico-laboratoriais e epidemiológicas foram confirmados três casos, dois ficaram como prováveis e um foi descartado.

Não foi possível estabelecer os pormenores de como o caso índice foi a óbito. Ademais, os familiares não queriam fornecer maiores dados à equipe de saúde, provavelmente, pelo temor de serem responsabilizados pela chegada da doença à comunidade e, além disso, pelo estigma que a peste tem na região. É importante lembrar que Jacocha é uma comunidade rural com habitantes tipicamente agricultores e onde os costumes ancestrais estão arraigados e muitas vezes a chegada de doenças é associada com sentimentos de culpa.

O diagnóstico de certeza na peste é dado pelo achado da Y. pestis. Embora não se tenha podido isolar o germe nos pacientes, é possível considerá-los como casos prováveis de peste, desde que a peste seja virtualmente a única infecção que, epidêmica e subitamente, apresente linfadenite, aguda com febre, rápido desenvolvimento do bubão e curso clínico fulminante que pode produzir a morte entre dois a quatro dias após o início dos sintomas ${ }^{5}$. O tempo entre o velório do caso índice e a apresentação do caso $n^{\circ} 1$, está dentro do tempo de incubação da peste o qual depende do inóculo e varia entre dois e oito dias, após picada de uma pulga infectada 4 .
De qualquer forma, conseguimos títulos considerados positivos de anticorpos contra Y. pestis por meio da hemaglutinação passiva. Somente em três dos pacientes foram obtidas duas amostras de sangue. A paciente $n^{\circ} 4$ é bem provável que também tenha sido um caso de peste, pelas características clínicas e epidemiológicas, mas preferimos desconsiderar pela negatividade da sorologia. Nos outros dois pacientes ( $n^{\circ} 3$ e $\left.n^{\circ} 5\right)$ não foi possível obter a segunda amostra pela dificuldade de serem localizados novamente ou por se recusarem à colheita da segunda amostra. Nesses dois pacientes, a primeira amostra foi positiva em altos títulos.

A infecção das duas crianças (caso $n^{\circ} 3$ e $n^{\circ} 4$ ) aparentemente estava relacionada à infecção da mãe, que esteve presente no velório do caso índice. Elas não tinham nenhum outro fator de risco que consiga explicar a aparição das características clínicas. A mãe deles (caso $n^{\circ} 2$ ) apresentou febre e bubão, além de sorologia seriada positiva.

Do ponto de vista epidemiológico é importante mencionar que todos os casos considerados prováveis tiveram relação com o velório do caso índice, o que é um fator de risco para a transmissão da doença devido à possibilidade da presença de pulgas infectadas. A circulação da Yesínia em toda a área foi confirmada pelo fato que 
onze cães ${ }^{1}$ de várias comunidades em torno de Jacocha apresentaram títulos considerados positivos. Já foi descrito ${ }^{37}$ que nas áreas em silêncio epidemiológico, cerca de $21 \%$ do total dos cães podem ter títulos sorológicos positivos e que nas áreas em atividade podem existir títulos positivos até em $49 \%$ dos cães ${ }^{2}$. A presença de cães positivos é conseqüência do contato do animal com roedores e marsupiais infectados, principalmente ao alimentar-se dos mesmo. As investigações sorológicas, entre os carnívoros, são rápidas e menos laboriosas do que entre os roedores, pelo que podem ser realizadas discretamente e evitando o inconveniente representado pela captura intradomiciliar de roedores ${ }^{2}$.
Vale a pena mencionar que o sistema de vigilância comunal foi realmente efetivo para detectar a presença da doença. A experiência prévia da mãe de uma das pessoas afetadas (caso $n^{\circ} 1$ ) foi de vital importância, pois reconheceu as características da doença e, por intermédio do vigilante comunitário da área, os profissionais da saúde ficaram sabendo da situação e levaram a notificação até o Hospital de Huancabamba.

O rápido acionamento dos profissionais da saúde e as medidas de controle conseguiram evitar outras mortes pois a letalidade nos casos sem tratamento situase acima do $50 \%$.

\section{AGRADECIMENTOS}

Os autores cumprimentam aos profissionais da saúde do Hospital de Huancabamba e da Direccion de Salud de Piura pela rápida e efetiva intervenção na área afetada.

\section{REFERÊNCIAS BIBLIOGRÁFICAS}

1. Almeida AM, Brasil DP, Leal NC, Melo ME, Rego RV, Almeida $\mathrm{CR}$. Estudos bacteriológicos e sorológicos de um surto de peste no Estado da Paraíba, Brasil. Memórias do Instituto Oswaldo Cruz 84: 249-256, 1989

2. Almeida AMP, Brasil DP, Melo MEB, Leal NC, Almeida CR. Importância dos carnívoros domésticos (cães e gatos) na epidemiologia da peste nos focos do Nordeste do Brasil. Cadernos de Saúde Pública. Rio de Janeiro 1:49-55, 1988.

3. Almeida AMP, Brasil DP, Nakazawa M, Almeida CR. Demonstração de atividade pestosa no foco da Serra dos Órgãos (RJ Brasil) através de exames sorológicos dos roedores. Revista de Microbiologia de São Paulo 16:280-281, 1985.
4. Butler T. Yersinia infections: centennial of the discovery of the plague bacillus. Clinical Infectious Diseases 19:655-663, 1994.

5. Butler T. Yersinia species (including plague) In: Mandell GL, Bennett J, Dolin R (eds) Principles and practice of infectious diseases. $4^{\text {th }}$ edition. New York. Churchill Livingstone, 1995.

6. Pan American Health Organization, Plague in the Americas. Washington DC 157-175, 1945.

7. Rust Jr JH, Miller BE, Bahmanyar M, Marshall Jr JD, Purnaveja $S$, Canaugh DC, Hla US. The role of domestic animals in the epidemiology of plague II Antibody to Yersinia pestis in sera of dogs and cats Journal of Infectious Diseases 124:527-531, 1971. 